\title{
IMPLEMENTASI KESELAMATAN LALU LINTAS PADA ANAK USIA DINI DENGAN METODE PENDEKATAN PEMBELAJARAN KOOPERTAIF TIPE ROLE PLAYING
}

\author{
Alfian Saleh*1, Muthia Anggraini ${ }^{2}$, Sean Marta Efastri ${ }^{3}$ \\ Universitas Lancang Kuning; Jl.Yos Sudarso Km.8 Rumbai \\ Program Studi Teknik Sipil Fakultas Teknik dan Program Studi PG PAUD Fakultas Keguruan \\ Ilmu Pendidikan Universitas Lancang Kuning \\ e-mail: alfian.saleh@unilak.ac.id
}

\begin{abstract}
The disciplined person can not be formed instantaneously, nor in the form of traffic discipline. Traffic education for early childhood is one way of preventing traffic accidents that can be planted early on. Safety education activities are part of community service conducted to students of kindergarten Alifa Kids 5. Community service is part of Tridharma Perguruan Tinggi. This activity aims to increase students' knowledge about safety in schools, especially regarding safety signs. Commander of the community is a method of implementation of this communit in the form of education followed by questions and answers and roleplay. This activity is done by cooperative method of role playing type where every student of student switch role become a role in this thing that is procedure of crossing. The result of this activity is student of kindergarten Alifa Kids 5 can play role in case crossing highway. The conclusion of this activity is the increase of students' knowledge about implementing traffic safety especially crossing the road. It is hoped that with increasing and implementing procedures to cross the right path can raise students' awareness for safe behaviors increase.
\end{abstract}

Keywords: Crossing the Road, Safety Education, Role Playing

\begin{abstract}
Abstrak
Pribadi yang disiplin tidak dapat dibentuk secara instan, demikian juga dalam membentuk kedisiplinan berlalu lintas. Pendidikan berlalu lintas bagi anak-anak usia dini merupakan salah satu cara pencegahan kecelakaan lalu lintas yang dapat ditanamkan sejak dini. Kegiatan pendidikan keselamatan merupakan bagian dari pelayanan masyarakat yang dilakukan kepada siswa siswi TK Alifa Kids 5. Pelayanan masyarakat merupakan bagian dari Tridharma Perguruan Tinggi. Kegiatan ini bertujuan untuk meningkatkan pengetahuan siswa tentang keselamatan di sekolah, terutama mengenai tanda-tanda keselamatan. Pangabdian masyarakat adalah metode implementasi komunitai ini dalam bentuk pendidikan yang diikuti dengan pertanyaan dan jawaban dan roleplay. Kegiatan ini dilakukan dengan metode kooperatif tipe role playing dimana setiap siswa siswi bertukar peran menjadi sebuah peran dalam hal ini yaitu tata cara menyeberang. Hasil dari kegiatan ini adalah siswa siswi TK Alifa Kids 5 mampu memainkan peran dalam kasus menyeberang jalan raya. Kesimpulan dari kegiatan ini adalah peningkatan pengetahuan siswa siswi tentang menerapkan keselamatan lalu lintas khsusnya menyeberang jalan. Diharapkan dengan meningkatnya dan menerapkan tata cara menyebarang jalan yang benar dapat menumbuhkan kesadaran siswa siswi untuk berperilaku aman meningkat.
\end{abstract}

Kata Kunci: Menyeberang Jalan, Pendidikan Keselamatan, Role Playing

\section{PENDAHULUAN}

Sekolah merupakan tempat bagi anak dapat memunculkan dan mengembangkan potensi terbaiknya. Ketika berada di sekolah, maka ia akan mendapatkan konsep-konsep yang mendasari pola pikir mereka. Salah satu tingkat pendidikan yan cukup penting dalam rangka menyiapkan 
generasi muda terdidik untuk bangsa dan Negara adalah pendidikan TK (Taman Kanak-kanak). Pada usia dini, anak-anak mudah untuk menyerap hal-hal baru baik itu bersifat positif maupun negative, untuk itu pada anak usia ini perlu penanaman nilai-nilai positif. Salah satunya pengetahuan tentang keselamatan lalu lintas.

Persoalan perilaku yang tidak disiplin tentu tak bisa diubah dengan cepat. Butuh waktu dan proses. Begitu juga dengan budaya keselamatan. Budaya keselamatan tak bisa diturunkan dari ayah atau ibu. Budaya keselamatan berlalu lintas di jalan raya harus dididik sedini mungkin, diajarkan dan diberikan pemahaman serta dilakukan secara terus menerus. Oleh sebab itu, perlu pendidikan usia dini tentang keselamatan berlalu lintas termasuk didalamnya membiasakan berperilaku disiplin ketika berlalu lintas.

Pembelajaran dan penyebaran materi keselamatan lalu lintas di jalan raya bagi anak-anak disusun dengan cara yang menarik dan menyenangkan. Hal ini dilakukan untuk memudahkan mereka memahami dan menerapkan dalam kehidupan sehari-hari. Salah satu pembelajaran yang menarik dan melibatkan peserta didik secara langsung yaitu metode pembelajaran tipe role playing (bermain peran). Dimana dengan bermain peran secara langsung baik sebagai objek maupun subjek dari aktivitas lalu lintas, anak-anak dapat lebih mudah memahami dan mengetahui apa yang salah dan apa yang seharusnya dilakuakn sebagai pemakai jalan dan pemakai kendaraan. Seperti yang kita ketahui, masa kanak-kanak merupakan fase awal dalam kehidupan manusia untuk memulai sosialisasi eksternal diluar lingkungan keluarga intinya dan pada fase ini mereka cenderung lebih mudah untuk menyerap nilai-nilai termasuk pengetahuan berlalu lintas karena pada nantinya jika mereka memasuki usia sekolah, remaja dan dewasa, mereka akan selalu beriteraksi dengan sistem lalu lintas dan jalan raya dalam menjalankan aktivitasnya.

\section{METODE}

Pembelajaran dengan role playing adalah suatu cara penguasaan bahan-bahan pelajaran melalui pengembangan imajinasi dan penghayatan siswa. Pengembangan imajinasi dan penghayatan itu dilakukan siswa dengan memerankannya sebagai tokoh hidup atau mati. Metode ini banyak melibatkan siswa dan membuat siswa senang belajar serta metode ini mempunyai nilai tambah yaitu dapat menjamin partisipasi seluruh siswa dan memberi kesempatan yang sama untuk menunjukkan kemampuannya dalam bekerjasama hingga berhasil dan permainan merupakan pengalaman yang menyenangkan bagi siswa.Adapun langkah-langkah Role Playing adalah sebagai berikut:

1. Menghangatkan suasana dan memotivasi peserta didik

Menghangatkan suasana kelompok termasuk mengantarkan peserta didik terhadap masalah pembelajaran yang perlu dipelajari. Hal ini dapat dilakuakn dengan mengidentifikasi masalah, menjelaskan masalah, menafsirkan cerita dan mengeksplorasi isu-isu, serta menjelaskan peran yang akan dimainkan.Tahap ini dimaksudkan untuk memotivasi peserta didik agar tertarik pada masalah. Karena itu tahap ini sangat penting dan paling menentukan keberhasilan. Bermain peran akan berhasil bila peserta didik menaruh minat dan memperhatikan masalah yang diajukan guru.

2. Memilih Peran

Dalam tahap ini, peserta didik dan guru mendeskripsikan berbagai watak atau karatketr apa yang mereka suka, bagaimana mereka merasakan dan apa yang harus mereka kerjakan, kemudian para peserta didik diberi kesempatan secara sukarela untuk jadi pemeran.

3. Menyusun tahap-tahap peran

Pada tahap ini, para pemeran menyusun garis-garis besar adegan yang akan diaminkan. Dalam hal ini, tidak perlu ada dialog khusus karena para peserta didik dituntut untuk bertindak dan berbicara secara spontan.

4. Meyiapkan pengamat

Sebaiknya pengamat dipersiapkan secara matang dan terlibat dalam cerita yang akan dimainkan agar semua peserta didik turut mengalami dan menghayati peran yang dimainkan dan aktif mendiskusikannya.

5. Pemeranan 
Pada tahap ini, para peserta didik mulai beraksi secara spontan, sesuai dengan peran masing-masing.pemeranan dapat berhenti apabila para peserta didik telah merasa cukup dan apa yang seharusnya mereka perankan telah dicoba untuk dilakukan. Dalam hal ini guru perlu menilai kapan bermain peran dihentikan

6. Diskusi dan evaluasi

Diskusi akan mudah dimulai jika pemeran dan pengamat telah terlibat dalam bermain peran, baik secara emosional maupun secara intelektual. Dengan melontarkan sebuah pertanyaan, para peserta didik akan segera terancing untuk diskusi

7. Pemeran ulang

Pemeranan ulang dilakukan berdasarkan hasil evaluasi dan diskusi mengenai alternatif pemeranan. Mungkin ada perubahan peran watak yang dituntut. Perubahan ini memungkinkan adanya perkembangan baru daalam upaya pemecahan masalah. Setiap perubahan peran akan mempengaruhi pern lainnya

8. Diskusi dan evaluasi tahap dua

Diskusi dan evaluasi pada tahap ini sama seperti pada tahap enam, hanya dimaksudkan untuk menganalisis hasil pemeranan ulang dan pemecahan maslah pada tahap ini mungkin sudah lebih jelas.

9. Membagi pengalaman dan mengambil kesimpulan

Pada tahap ini, peserta didik saling mengemukakan pengalaman hidupnya dalam berhadapan dengan orang tua, guru, teman dan sebagianya.Semua pengalaman peserta didik dapat diungkapkan atau muncul secara spontan

\section{HASIL DAN PEMBAHASAN}

Pelaksanaan program pengabdian masyarakat ini berupa pendidikan keselamatan di TK Alifa Kids 5 ini diikuti oleh kurang lebih 30 orang siswa siswi TK. Kegiatan diawali dengan salam, perkenalan dan menghangatkan suasana kelas kepada anak-anak dengan memberikan nyanyian, sapaan dan tepuk tangan.

Setelah itu diberikan maeri oleh pemateri dengan menjelaskan slide yang berisi banyak gambar dan terfokuskan kepada traffic light dan cara menyeberang jalan di daerah persimpangan dan yang memiliki zebra cross. Materi yang diberikan dilakukan secara dua arah kepada siswasiswi TK. Setelah materi slide dijelaskan kemudian anggota lainnya memberikan alat peraga berupa mobi mobilan, gambar lampu merah, lampu kuning dan lampu hijau serta boneka orang untuk menyeberang.

Selanjunya dilakukan pada tahap bermain peran. Untuk pertama anggota memperagakan cara-cara orang untuk menyeberang. Dbutuhkan sebanyak 6 enam orang untuk memgang alat peraga yaitu yang menjadi lampu merah, yang menjadi lampu kuning, yang menjadi lampu hijau, yang menjadi mobil, yang menjadi boneka orang pertama dan yang menjadi boneka orang kedua.

Setelah itu mensimulasikan peran dengan aba-aba oleh pemateri yang dalam hal ini dibantu oleh ibu guru dan kemudian dilakukan pengamatan oleh anggota tim lain sejauh mana antusias anak memperhatikan peragaan tersebut..

Kemudian terakhir tim pengabdian melakukan kegiatan demonstrasi penerapan rambu keselamatan. Demonstrasi berupa role play dimana tim pengabdian berperan sebagai narrator sedangkan para siswa siswi yang sukarela mengajukan diri sebagai sukarelawan berperan sebagai pemain peran dari cerita yang diberikan. Para siswa siswi lainnya yang berperan sebagai penonton juga ikut terlibat aktif selama berlangsungnya role play. Berdasarkan demonstrasi ini dapat disimpulkan bahwa siswa siswi sudah mengetahui rambu-rambu keselamatan yang dapat diterapkan dan juga mengerti akan arti dari rambu-rambu tersebut.

Secara keseluruhan acara ini berlangsung dengan baik, sesuai dengan waktu yang ditentukan dan mendapatkan atensi yang cukup baik dari seluruh pihak sekolah. Adapun kendala yang ditemukan adalah dalam membuat tertib siswa siswi agar disiplin dalam duduk berbaris selama mengikuti kegiatan dan juga membuat siswa siswi tetap fokus selama berlangsungnya kegiatan. Fun learning yang diterapkan dapat membuat $75 \%$ siswa siswi benar-benar mengikuti jalannya kegiatan dengan optimal. Kegiatan ini dapat dilihat dari gambar-gambar berikut ini: 

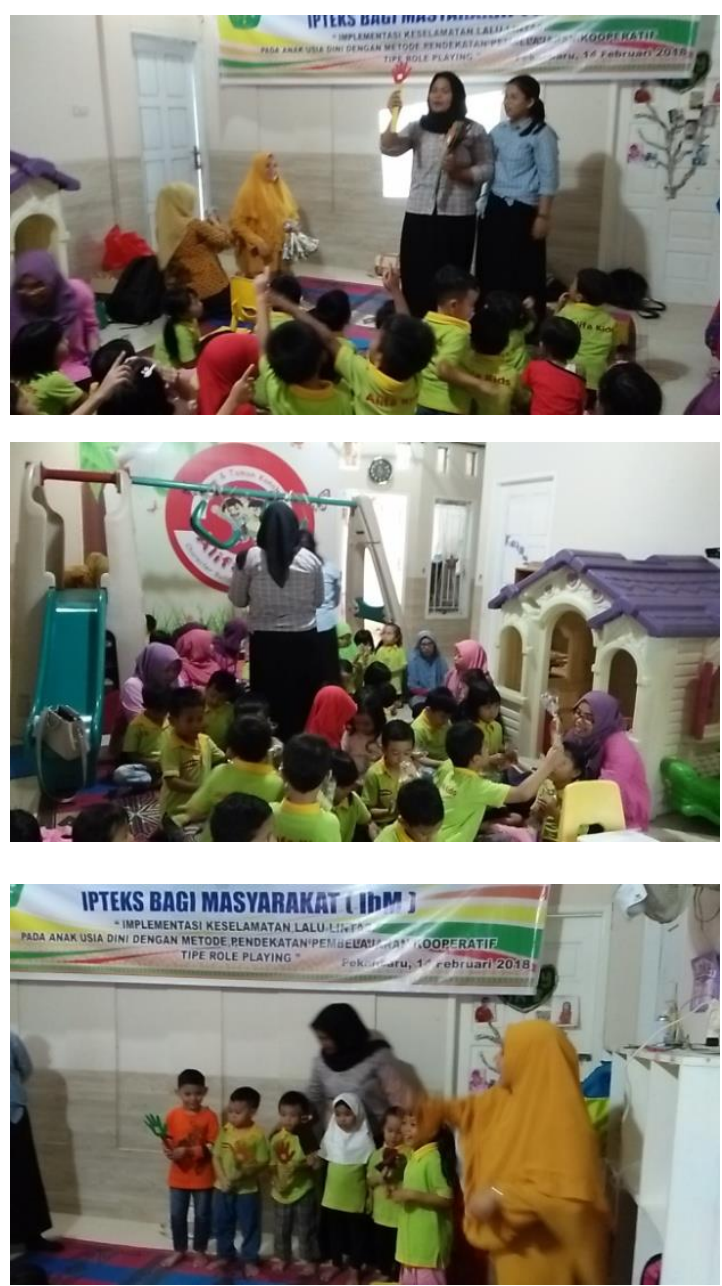
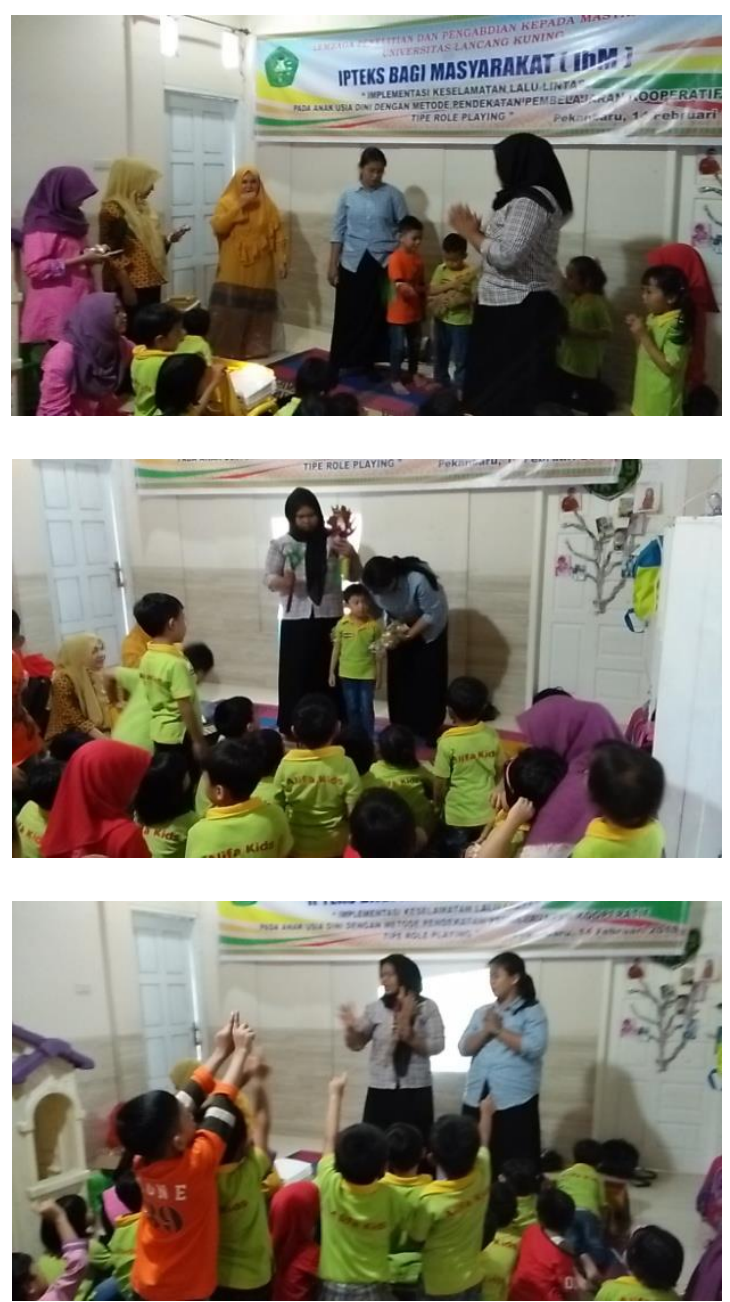

Gambar 2. Foto-foto Saat Pelaksanaan Kegiatan Pengabdian

Pemahaman anak akan keselamatan dirinya tidak terlepas dari keterbatasan kognitif yang dimilikinya. Anak usia sekolah sebenarnya sudah mampu membedakan arti dari konsep selamat dan tidak selamat, namun karena perkembangan kognitif mereka masih berada pada tahap praoperasioanl yang salah satunya bercirikan ketidakmampuan menggunakan sudut pandangnya sendiri (egosentrisme), maka dalam situasi praktis, anak-anak lebih mengandalkan interpretasi mereka sendiri tentang apa yang dianggap selamat dan tidak selamat (Maakip,dkk.,2000). Sebagai contoh, anak-anak pada usia ini mengira jika mereka bisa melihat pengendara kendaraan bermotor mendekati mereka yang sedang menyeberang jalan, maka pengendara tersebut juga bisa melihat mereka dengan jelas. Anak-anak ini tidak mempertimbangkan adanya kemungkinan pandangan pengendara kendaraan bermotor bisa terhalang oleh banyak hal, seperti tikungan tajam sebagai akibat dari ketidakakuratan penilaian ini, anak-anak yang usianya muda rentan mengalami kecelakaan di jalan raya, bahkan di jalan raya sekalipun. Notoatmodjo (2007) menjelaskan pendidikan mempengaruhi pengetahuan. Adapun faktor-faktor lain yang mempengaruhi pengetahuan seseorang antara lain adalah usia, pendidikan, pengalaman, media massa dan sosial budaya.

\section{KESIMPULAN}

Beberapa kesimpulan dari kegiatan pengabdian masyarakat ini adalah cara meningkatkan pengetahuan anak usia dini tentang keselamatan lalu lintas dilakukan dengan metode pembelajaran 
kooperatif tipe role paying yaitu dengan bermain peran secara langsung baik sebagai objek maupun sebagai subjek dari aktivitas lalu lintas sehingga anak-anak dapat lebih mudah memahami dan mengetahui apa yang salah dan apa yang seharusnya dilakukan ketika berperan sebagai pemakai jalan dan pemakai kendaraan studi kasusnya dalam hal menyeberang jalan dan dengan dilakukan implementasi menggunakan pendekatan kooperatif tipe role playing ini sebagai upaya tentang peningkatan pengetahuan tentang keselamatan lalu lintas anak usia dini. Pemahaman anak pada setiap aspek keselamatan diri mungkin saja dibentuk oleh lingkungan sosial disekitarnya, terutama orang tua dan sekolah. Orang tua perlu lebih berperan aktif dengan mengajarkan secara langsung kepad anak mengenai etika berlalu lintas seuai dengan aturan yang berlaku.

\section{SARAN}

Berdasarkan simpulan di atas, maka saran yang dapat diberikan adalah sebagai berikut:

1. Pada saat pembelajaran kooperatif metode tipe role playing diterapkan, perlu memperhatikan petunjuk-petunjuk yang diberikan dalam memainkan sebuah peran sehingga peran yang dimainkan akan lebih mudah dipahami

2. Diharapkan agar dapat menerapkan metode pembelajaran metode kooperatif tipe role playing sebagai alternayif atau pilihan dalam praktik pembelajaran keselamatan lalu lintas karena terbukti dapat meningkatkan pemahaman siswa siswi tentang keselamatan lalu lintas.

\section{DAFTAR PUSTAKA}

[1] Jamal ma'mur asmani. 2009. Manajemen strategis Pendidikan Anak Usia Dini. Yogyakarta: DIVA press.

[2] Peraturan Menteri Perhubungan Republik Indonesia Nomor PM 13 Tahun 2014 tentang Rambu Lalu Lintas

[3] Peraturan Menteri Perhubungan Republik Indonesia Nomor PM 34 Tahun 2014 tentang Marka Jalan

[4] Maakip,L, Sulaiman, W.S.W., Ismail,R, \& Jaafar, W.A.W. (2000), Pengetahuan kanakkanak terhadap aspek-aspek keselamatan diri: Satu kajian awal Seminar Psikologi-Psima

[5] Mulyasa. 2003. Kurikulum Berbasis Kompetensi Konsep; Karakteristik dan Implementasi. Bandung: PT.Remaja Rosdakarya..

[6] Best Practices In Geographic Information Systems-Based Transportation Asset Management: Off

[7] Hinze, J., and Bren, K. (1997). "The Causes of Trenching Related Fatalities and Injuries, "Proceedings of Construction Congress V: Managing Engineered Construction in Expanding Global Markets, ASCE, pp 389-398.

[8] King, R.W. and Hudson, R. (1985). "Construction Hazard and Safety Handbook: Safety." Butterworths, England.

[9] Sujiono, Yuliani Nurani.2009.Konsep Dasar Pendidikan Anak Usia Dini.Jakarta 